\title{
Spectral estimation of in-vivo wheat chlorophyll a/b ratio under contrasting water availabilities
}

\author{
Gabriel Mulero, Harel Bacher, Uri Kleiner, Zvi Peleg and Ittai Herrmann ${ }^{*}$
}

The Robert H. Smith Institute of Plant Sciences and Genetics in Agriculture, The Hebrew University of Jerusalem, Rehovot, 7610001, Israel.

\section{*Corresponding author:}

Ittai Herrmann

The Robert H. Smith Institute of Plant Sciences and Genetics in Agriculture, The Robert H. Smith Faculty of Agriculture, Food and Environment, The Hebrew University of Jerusalem, P.O. Box 12, 7610001 Rehovot, Israel.

Tel: +972-8-9489757

E-mail: Ittai.Herrmann@mail.huji.ac.il

Main Conclusion Hyperspectral non-destructive estimation of chlorophyll a/b ratio 
Abstract To meet the ever-growing global population necessities, it is needed to identify climate change-relevant plant traits to integrate into breeding programs. Developing new tools for fast and accurate estimation of chlorophyll parameters, chlorophyll a (Chl-a), chlorophyll b (Chl-b) content, and their ratio $(\mathrm{Chl}-\mathrm{a} / \mathrm{b})$, can promote breeding programs of wheat with enhanced climate adaptively. Spectral reflectance of leaves is affected by changes in pigments concentration and can be used to estimate chlorophyll parameters. The current study identified and validated the top spectral indices known and developed new vegetation indices (VIs) for Chl-a and Chl-b content estimation and used them to non-destructively estimate $\mathrm{Chl}-\mathrm{a} / \mathrm{b}$ values and compare them to hyperspectral estimations. Three wild emmer introgression lines, with contrasting drought stress responsiveness dynamics, were selected. Well and limited irrigation irrigation regimes were applied. The wheat leaves were spectrally measured with a handheld spectrometer to acquire their reflectance at the 330 to $790 \mathrm{~nm}$ range. Regression models based on calculated VIs as well as all hyperspectral curves were calibrated and validated against chlorophyll extracted values. The developed VIs resulted in high accuracy of Chl-a and ChI-b estimation allowing indirect non-destructive estimation of $\mathrm{Chl}-\mathrm{a} / \mathrm{b}$ with root mean square error (RMSE) values that could fit 6 to 10 times in the range of the measured values. They also performed similarly to the hyperspectral models. Altogether, we present here a new tool for a non-destructive estimation of $\mathrm{Chl}-\mathrm{a} / \mathrm{b}$ which can serve as a basis for future breeding efforts of climate-resilience wheat as well as other crops.

Keywords: Hyperspectral, Phenotyping, Pigment, Wild emmer, Drought 


\begin{tabular}{|c|c|}
\hline ANOVA & Analysis of variance \\
\hline Cal & Calibration \\
\hline Chl-a & Chlorophyll a \\
\hline $\mathrm{Chl}-\mathrm{a} / \mathrm{b}$ & Chlorophyll a and chlorophyll b ratio \\
\hline Chl-b & Chlorophyll b \\
\hline DAT & Days after transplant \\
\hline ILs & Introgression lines \\
\hline$n$ & number of samples \\
\hline NDSI & Normalized difference spectral index \\
\hline PLSR & Partial least squares regression \\
\hline $\mathrm{R}$ & Correlation coefficient \\
\hline $\mathrm{R}^{2}$ & Coefficient of determination \\
\hline RMSE & Root means square error \\
\hline RMSEP & Root mean square error of prediction \\
\hline RMSEPC & Root means square error of prediction of calibration \\
\hline RMSEPV & Root means square error of prediction of validation \\
\hline TChl & Total chlorophyll \\
\hline Val & Validation \\
\hline VIs & Vegetation indices \\
\hline WL & Water-limited \\
\hline WW & Well-watered \\
\hline
\end{tabular}




\section{Introduction}

Current and projected climate change, as express in the increasing intensity of erratic climate events across extensive regions of the planet, threaten to increase food insecurity worldwide (Myers et al. 2017). To meet the ever-growing global population demands for food, feed, fibers, and bioenergy plant-based products, a significant increase in crop-plant production is required (reviewed by Sade and Peleg 2020). Thus, there is an urgent need to develop climate change resilience crop-plants with enhancing yield and nutritional quality. A fundamental aspect of such an effort is the identification of key functional traits that can be integrated into breeding programs to complement the changing agro-systems.

Chlorophyll is an important light-absorbing photosynthetic pigment largely determining the plant's photosynthetic capacity and as consequence its growth and development (Croft et al. 2017). It includes the chlorophyll a (Chl-a), which is the primary electron donor with in the reaction center, and chlorophyll-b (Chl-b), a light-harvesting accessory pigment found in the antenna complexes of the light-harvesting complexes of photosystem II (Croce and van Amerongen 2014; Croft and Chen 2018). The ratio between chlorophyll $a$ and $b(\mathrm{Chl}-\mathrm{a} / \mathrm{b})$ is affected by the plant's natural senescence processes and various environmental cues (Lenaerts et al. 2019). Under water stress, the Chl-b degrades into Chl-a, leading to a higher $\mathrm{Chl}-\mathrm{a} / \mathrm{b}$ (Guo et al. 2016). Thus, developing new tools for fast and accurate estimation of chlorophyll parameters can promote breeding programs of crop-plants with enhancing climate adaptively.

Quantification of chlorophyll content in plant leaf samples was established by integrating empirical models of spectrophotometry measurement of light transmission wavelengths based on Beer-Lambert law (Moran and Porath 1980; Wellburn 1994). While resulting in accurate 
chlorophyll content, they are destructive, labor-intensive, time-consuming, and do not allow to study the longitudinal and spatio-temporal dynamics over time (Gitelson et al. 2006; Gitelson et al. 2003; Lopes et al. 2017). Alternatively, an in-vivo non-destructive optical hand-held absorbance-based total chlorophyll (TChl) meter (such as SPAD-502; Minolta corporation Ltd., Osaka, Japan) can be used. It can obtain a quick prediction of TChl content, but in many cases, the SPAD values are not calibrated to actual TChl content (Yamamoto et al. 2002; Joynson et al. 2021), and cannot estimate Chl-a, Chl-b and their ratio. Hyperspectral data is an alternative non-destructive approach, based on extracting reflectance values for hundreds of narrow spectral bands (Thenkabail et al. 2013). These data can be used for building models to determine TChl, Chl-a and Chl-b content as well as Chl-a/b. Spectral reflectance of leaves is strongly affected by changes in pigments concentration that are negatively related to spectral reflectance (Chappelle et al. 1992; Gitelson et al. 2005; Yu et al. 2015). A vegetation index (VI) is a mathematical manipulation based on reflectance values from two or more spectral bands (Bannari et al. 1995) used to estimate plant traits and monitor their health and condition (Giovos et al. 2021). Spectral data and VIs are analyzed to estimate chlorophyll content in vegetation (Bannari et al. 2007; Banerjee et al. 2020; Chen et al. 2020; Croft and Chen 2018; Gitelson 2011; Main et al. 2011; Sonobe et al. 2020).

Wheat (Triticum sp.) is one of the world's most consumed crops, with production estimated at $\sim 770$ million tons per annum (http://www.fao.org/faostat). To meet the rising demand of the projected 9.7 billion people by 2050, an increase of at least $60 \%$ in wheat production is required (Ray et al. 2013). Wheat domestication and subsequent evolution under domestication involved a suite of complex genetic, morphological, anatomical, and physiological 
modifications (Abbo et al. 2014; Golan et al. 2018). Wild emmer wheat [T. turgidum ssp. dicoccoides (Körn.) Thell.], the direct allotetraploid (2n=4x=28; genome BBAA) progenitor of domesticated wheats, thrives across wide eco-geographic amplitude across the Fertile Crescent and offers ample allelic repertoire for agronomically important traits, including drought tolerance (e.g., Bacher et al. 2021; Peleg et al. 2005).

Recently we evaluated a large set of wild emmer wheat introgression lines (ILS) under contrasting water availabilities and identified promising drought tolerance strategies (Bacher et al. 2021). Here we applied a field-based evaluation of selected ILs with divergent water-stress responsiveness and tested their $\mathrm{Chl}-\mathrm{a} / \mathrm{b}$ ratio alteration in response to water stress. Our working hypothesis was that $\mathrm{Chl}-\mathrm{a} / \mathrm{b}$ can be assessed non-destructively in-vivo wheat leaves based on Chl-a and Chl-b contents. The specific objectives of the current study were to: $i$ ) identify and validate the best VIs for Chl-a and Chl-b, ii) use the best VIs to assess $\mathrm{Chl}-\mathrm{a} / \mathrm{b}$ under contrasting water availabilities, and iii) compare VIs- and hyperspectral- based Chl-a/b estimation models. Altogether, we showed here for the first time, to the best of our knowledge, a new tool, based on a spectral assessment of Chl-a and Chl-b for non-destructive estimation of $\mathrm{Chl}-\mathrm{a} / \mathrm{b}$ which can serve as a basis for future breeding efforts of climate-resilience wheat, as well as other crops.

\section{Material and Methods}

\subsection{Plant material and experimental design}

Previously we characterized a set of adaptive wild emmer introgression lines (ILS; $\mathrm{BC}_{3} \mathrm{~F}_{5}$ ) for their drought responsiveness strategies. For the current study, we selected three lines (IL46, 
IL82, IL105) with contrasting drought stress responsiveness dynamics (Bacher et al. 2021). IL46 was characterized as highly productive and stable and exhibited high growth and gas exchange under water stress. IL82 was characterized as highly productive and exhibited high growth under water stress with phenotypic plasticity (i.e., its physiological and morphological parameters were changing due to the water stress). IL105 was characterized to have lower biomass productivity under water stress and define as high phenotypic plasticity. Each line consists of few introgressions from the wild emmer line Zavitan, with IL46 consists of six introgressions that cover $5.2 \%$ of the genome, IL82 consists of fifteen introgressions that cover $13.37 \%$ of the genome, and IL105 consist of six introgressions that cover $6.07 \%$ of the genome (Supplementary Table S1).

The plants were grown during the winter of 2019-2020 at the experimental farm of The Hebrew University of Jerusalem in Rehovot, Israel (34 47' N, 31 54' E: 54 m above sea level) in a plastic-covered net house. The soil is brown-red degrading sandy soil (Rhodoxeralf) composed of $76 \%$ sand, $8 \%$ silt, and $16 \%$ clay. A split-plot factorial (genotype $\mathrm{x}$ irrigation regime) design was employed with two irrigation regimes split into 12 sub-plots, with four replicates (total 24 plots). Each plot of $150 \mathrm{~cm}$ long consisted of four planted rows. Plants were spaced $10 \mathrm{~cm}$, within and between rows resulting in 60 plants per plot. Two irrigation regimes were applied via a drip irrigation system: well-watered control (WW) and water-limited (WL). The WW treatment was irrigated weekly with a total amount of $\sim 750 \mathrm{~mm}$, whereas the WL treatment was irrigated every other week with a total amount of $\sim 250 \mathrm{~mm}$ (Supplementary Fig. S1). Water was applied during the winter months (Jan- Mar) to mimic the natural pattern of rainfall in the 
eastern Mediterranean region. The experiment was treated with fungicides and pesticides to control fungal pathogens or insect pests and was weeded manually once a week.

\section{Data collection}

Spectral data were acquired by PolyPen RP410 UVIS (PSI Ltd., Drasov, Czech Republic) in contact with the adaxial leaf side. The PolyPen is a leaf contact active spectrometer covering the range of 330 to $790 \mathrm{~nm}$ in $1 \mathrm{~nm}$ intervals ( $8 \mathrm{~nm}$ band width at full width half max). Before spectral data collection and in-between measurements, white reference measurement was acquired using a spectralon panel (PSI Ltd., Drasov, Czech Republic). Each selected leaf was in vivo spectrally measured five times to result in an average spectrum. The youngest fully developed leaf was selected for spectral data collection and sampling, starting the third until the ninth measuring date the flag-leaf was measured. In each plot, three leaves from different plants were marked and spectrally measured to represent the plot. The spectral data acquisition was followed by leaf sample collection. The leaves were cut from the plant into an air-tight polyethylene sealed bag and then placed into an ice-filled container for up to 2 hours before further laboratory measurements.

Five leaf discs $(0.8 \mathrm{~cm}$ diameter $)$ were taken from each leaf and placed in a glass container with $10 \mathrm{ml}$ of organic solvent (N.N Dimethylformamide) and transported into a dark $4^{\circ} \mathrm{C}$ incubator for $48 \mathrm{hrs}$. Then, the samples were pipette into $3 \mathrm{ml}$ quartz cuvettes in the UV/VIS Spectrophotometer (ST-VS-723; Lab-Fac instrument Ltd., Kowloon, Hong Kong) to acquire transmittance in two wavelengths: 647 and $664 \mathrm{~nm}$. The transmittance values were used to calculate the Chl-a, Chl-b, and TChl content $\left(\mathrm{mg} \mathrm{cm}^{-2}\right)$, as described previously (Moran 1982). 
Three plants per plot were sampled, the spectral and chlorophyll contents were averaged per plot.

\section{Data preprocessing and analyses}

Analysis of Variance (ANOVA) was used to assess the possible effects of genotype, irrigation regimes, data collection dates, and the different levels of interactions on the chlorophyll responses.

Thirty-three well-known VIs were pre-programmed to be calculated by the PolyPen sensor (Supplementary Table S2). The quality of the correlation between each of the VIs and Chl-a, Chlb, and TChl content was evaluated by the correlation coefficient (R). VIs resulting in R absolute values equal to or higher than 0.5 were selected for linear regression to produce a coefficient of determination $\left(\mathrm{R}^{2}\right)$ and root mean square error of prediction (RMSEP). Data sets were randomly selected with an even distribution on genotype by irrigation regime by date for all parameters based on the number $(n)$ of samples involved; Chl-a ( $n=168)$, Chl-b $(n=167)$ and TChl $(n=166)$, at a $70 \%$ and $30 \%$, calibration and validation, respectively. The calibration data sets were used to perform a linear regression analysis between each of $\mathrm{Chl}-\mathrm{a}, \mathrm{Chl}-\mathrm{b}$, and $\mathrm{TChl}$ content (dependent) and each of the selected VIs (independent) variables and determine the slope and intercept to be tested by the validation data sets. The predicted $\mathrm{Chl}-\mathrm{a}, \mathrm{Chl}-\mathrm{b}$, and $\mathrm{TChl}$ content values were compared to the observed values to obtain the calibration and validation $R^{2}$ (Cal and Val $R^{2}$, respectively) as well as RMSEP of calibration and validation (RMSEPC and RMSEPV, respectively) as calculated by (Herrmann et al. 2010). The \% RMSEPC and \% RMSEPV were calculated based on the RMSEPC and RMSEPV values out of the range of Cal and Val samples, respectively. The 
statistical analyses were applied in JMP 15 pro version statistical package (SAS Institute, Cary, NC, USA).

To find the best two bands combination for $\mathrm{Chl}-\mathrm{a}, \mathrm{Chl}-\mathrm{b}$, and $\mathrm{TChl}$ content spectral estimation, the normalized difference spectral index (NDSI; Inoue et al. 2008) was calculated, analyzed and ranked based on $\mathrm{R}^{2}$ values of a linear regression between each $\mathrm{Chl}-\mathrm{a}, \mathrm{Chl}-\mathrm{b}$, and TChl content (Supplementary Table S2). The highly ranked NDSI for each of the three chlorophyll parameters (i.e., Chl-a, Chl-b, and TChl content) was used for calibration and validation process as done with all selected VIs. The models' quality was assessed by $\mathrm{R}^{2}, \mathrm{RMSE}$ and \% RMSE. NDSI analysis was performed in R (version 3.4.1.) environment and statistical analyses were applied in JMP 14 pro version statistical package (SAS Institute, Cary, NC, USA).

In spectral datasets, as in the current study, there is high collinearity among variables (i.e., adjacent wavelengths), partial least squares regression (PLSR) is a commonly applied method (Singh et al. 2015; Wold et al. 2001; Yang et al. 2017) that used the information at all wavelengths to provide quantitative determination plant traits. To calculate the estimated trait by the regression equation, each wavelength receives a coefficient, the absolute value of these coefficients indicates the importance of each wavelength to the model. The Cal and Val samples distribution were the same as for the VIs analysis and the models' quality was assessed by $\mathrm{R}^{2}$, RMSE and \% RMSE. The statistical analysis was performed in python 3.8 with pandas (McKinney 2010), version 1.3, SciPy (Virtanen et al. 2020), version 1.6, and scikit-learn (Pedregosa et al. 2011), version 0.24, PLSR with NIPALS algorithm.

\section{Result and Discussion}


To test the effect of water availability on the accuracy of various non-destructive spectral models to estimate the $\mathrm{Chl}-\mathrm{a} / \mathrm{b}$ ratio we used three selected wild emmer wheat introgression lines (ILS) that represent contrasting stress responsiveness strategies (L46, IL82 and IL105; see Bacher et al. 2021). Characterization of these ILs under two contrasting water availabilities showed a clear effect of the irrigation regime on plant height and productivity (Supplementary Table S3 and Supplementary Fig. S2). In general, under water stress, all genotypes exhibited a significant reduction in height, vegetative dry weight and the final grain yield. These results indicate that the applied water stress had a significant impact on crop production and thus can serve as a good experimental platform for studying the potential of various VIs (Supplementary Table S2) to estimate chlorophyll content.

The genotypes had a significant effect on leaf Chl-a, Chl-b, TChl, and Chl-a/b $(P<0.0001)$, and the irrigation regimes affected significantly only the Chl-b and $\mathrm{Chl}-\mathrm{a} / \mathrm{b} \quad(P=0.024$ and $P=0.021$, respectively), but not on $\mathrm{Chl}-\mathrm{a}$ and $\mathrm{TChl}(P=0.229$ and $P=0.610$, respectively) (Supplementary Table S4). In wheat, Ashraf and Harris (2013) showed that Chl-a increased in response to drought, and tolerant cultivars exhibited a slight increase in the $\mathrm{Chl}-\mathrm{a} / \mathrm{b}$. In the current study, $\mathrm{Chl}-\mathrm{a} / \mathrm{b}$ values decline along with the development of the experiment and showed non-significant differences between irrigation treatments (Supplementary Fig S3a). The spectral reflectance curves of the fully developed leaf were similar to those of the flag-leaf but in a closer look, the earlier is not following the chronological trend of the latter in the visible spectral region (Supplementary Fig. S3b). The chronological trend is visible around $730 \mathrm{~nm}$. This mismatch in chronology led to a model based on the flag-leaf data alone. Leaf structure and pigment content affect leaf spectral reflectance (Gausman and Allen 1973). The relatively high 
mesophyll cell number per leaf area of flag-leaf in comparison to the fully developed leaf (Pyke et al. 1990) and variability in leaf thickness (Guru et al. 2017) may explain the lower reflectance of the fully developed leaves in the range of $740-780 \mathrm{~nm}$. Thus, it was expected to observe a reduction in the ability of spectral data to explain the variability in Chl-a and Chl-b content while analyzing the two leaf types together. Chl-b had the biggest advantage, in $\mathrm{R}$ values, for analyzing only the flag-leaf spectral data rather than the two leaf types together (Supplementary Fig. S4). To improve the quality of chlorophyll spectral estimation in in-vivo wheat leaves and develop a standardized data collection methodology the flag-leaf data alone was further analyzed. The focus of the current study is at Chl-a/b based on Chl-a and Chl-b spectral estimation, nevertheless, TChl that is commonly assessed, was discussed as an additional relevant output. Although leaf reflectance in the visible spectral region is negatively related to chlorophyll content (Gausman and Allen 1973) the calculated VIs can be either positively or negatively related to chlorophyll content based on the bands used and the structure of the VI equation. It was hypothesized that the combination of GM1 (Gitelson and Merzlyak 1997) positively related to chlorophyll content and Carter 1 (Carter 1994) negatively related to chlorophyll content will improve the chlorophyll estimation quality. Two VIs were developed (\#38 and \#39 in Supplementary Table S2) and proved to be at the top of TChl estimation and with higher $\mathrm{R}^{2}$ and smaller RMSE than each of their components alone (Table 1 ).

Vegetation indices (VIs) enable non-destructive and accurate assessment of leaf chlorophyll content 
The $\mathrm{R}^{2}$ distribution of the two bands combinations to assess $\mathrm{Chl}-\mathrm{a}, \mathrm{Chl}-\mathrm{b}$ and TChl content are presented in heat maps (Fig. 1a, $c$ and e). As expected the heat maps are similar for the three chlorophyll parameters (Datt 1998) but with smaller areas with relatively high $\mathrm{R}^{2}$ values for Chl-b. The selected bands for Chl-a and TChl are very similar as can be expected since Chl-a is the major parameter in TChl. It is important to mention that bands adjacent to the selected ones will also show high $\mathrm{R}^{2}$ values (Table S5). The best two bands combination for the Chl-b estimation was 406 and 525 nm, supported by Ustin and Jacquemoud (2020) reporting Chl-b absorption peaks in the blue and green regions. Analyzing the averaged spectral and destructive replicates per day (Fig. 1 b, $d$ and f) resulted in bigger $R^{2}$ values than the nonaveraged ones (Fig. 1a, c and e). All VIs were correlated to Chl-a, Chl-b and TChl and ranked based on $\mathrm{R}^{2}$ values (Supplementary Table S6). The top 10 performing VIs (Supplementary Table S6) used for Chl-a, Chl-b, and TChl estimation resulted in similar Cal and Val $\mathrm{R}^{2}$ as well as RMSE values (Table 1). The RMSE values (Fig. 3 and Table 1) of indices developed in the current study are smaller than $10 \%$ of the active ranges of $\mathrm{Chl}-\mathrm{a}, \mathrm{TChl}$ and even of $\mathrm{Chl}-\mathrm{b}$. Previous studies as detailed by Hallik et al. (2017) presented smaller $\mathrm{R}^{2}$ and bigger RMSE values of Chl-a and Chl-b estimation based on spectral data and stated that studies estimating Chl-b used VIs that were more strongly correlated to Chl-a. In the current study, VIs were developed specifically for Chl-a as well as Chl-b estimation and are at the top in their category (Table 1). Banerjee et al. (2020) developed a VI highly correlating with $\mathrm{Chl}-\mathrm{a}$, Chl-b and TChl concentrations based on wheat canopy side view imagery, acquired in a semi-controlled indoors environment. This VI used spectral regions related to nitrogen (1654 nm) and chlorophyll $(727 \mathrm{~nm})$. Sonobe et al. (2020) applied spectral methods to estimate leaf $\mathrm{Chl}-\mathrm{a}$ and $\mathrm{Chl}-\mathrm{b}$ in wasabi grown in a semi-controlled 
environment indoors and resulted in RMSE values similar to the values achieved in the current study (Table 1). The current study presented improvement (in terms of $R^{2}$ and RMSE) in the ability to estimate leaf $\mathrm{Chl}-\mathrm{a}, \mathrm{Chl}-\mathrm{b}$ and $\mathrm{TChl}$ content values in wheat grown under field conditions and used the spectrally estimated values to calculate Chl-a/b (Fig. 2). Spectral estimation of $\mathrm{Chl}-\mathrm{a} / \mathrm{b}$ was rarely published, Sonobe et al. (2020) directly estimated Chl-a/b by spectral means resulting in RMSE values ranging from 0.13 to 0.6 . In the current study, the RMSE can fit five to six times in the range of measured $\mathrm{Chl}-\mathrm{a} / \mathrm{b}$ values (Fig. 2a). To the best of our knowledge, the approach of spectrally estimating Chl-a and Chl-b values in in-vivo wheat leaves to calculate $\mathrm{Chl}-\mathrm{a} / \mathrm{b}$ was not published yet. The VIs developed in the current study were using two or few spectral bands while the PLSR applied hundreds of spectral bands to estimate Chl-a and Chl-b values.

Table 1: The top ten predictions for Chl-a, Chl-b, and TChl are presented based on all 33 Vls, NDSI generated VIs from the leaf reflectance spectra by the PolyPen sensor.

\begin{tabular}{|c|c|c|c|c|c|c|c|c|}
\hline Ranking $^{1}$ & VI & Cal $R^{2}$ & $\begin{array}{l}\text { RMSEPC } \\
\left(\mu \mathrm{g} \mathrm{cm}^{-2}\right)\end{array}$ & \% RMSEPC & Val $R^{2}$ & $\begin{array}{l}\text { RMSEPV } \\
\left(\mu \mathrm{g} \mathrm{cm}^{-2}\right)\end{array}$ & \% RMSEPV & References \\
\hline Chl-a & & $(n=118)$ & & & $(n=50)$ & & & \\
\hline 1 & $\mathrm{NDSI}_{415,614}$ & 0.85 & 2.34 & 8.61 & 0.87 & 2.02 & 9.24 & Current study \\
\hline 2 & $\mathrm{ZMI}$ & 0.82 & 2.52 & 9.30 & 0.80 & 2.47 & 11.31 & Zarco-Tejada et al. (2001) \\
\hline 3 & Clred-edge & 0.82 & 2.54 & 9.37 & 0.81 & 2.43 & 11.10 & Gitelson et al. (2005) \\
\hline 4 & Carter 1 & 0.82 & 2.57 & 9.45 & 0.82 & 2.38 & 10.89 & Carter (1994) \\
\hline 5 & Clgreen & 0.81 & 2.61 & 9.60 & 0.83 & 2.28 & 10.42 & Gitelson et al. (2005) \\
\hline 6 & GM1 & 0.81 & 2.62 & 9.64 & 0.83 & 2.28 & 10.43 & Gitelson and Merzlyak (1997) \\
\hline 7 & GM2 & 0.82 & 2.57 & 9.46 & 0.80 & 2.48 & 11.37 & Gitelson and Merzlyak (1997) \\
\hline 8 & NDRE & 0.81 & 2.62 & 9.66 & 0.80 & 2.47 & 11.31 & Barnes et al. (2000) \\
\hline
\end{tabular}




\begin{tabular}{|c|c|c|c|c|c|c|c|c|}
\hline Ranking $^{1}$ & VI & Cal $R^{2}$ & $\begin{array}{l}\text { RMSEPC } \\
\left(\mu \mathrm{g} \mathrm{cm}^{-2}\right)\end{array}$ & $\%$ RMSEPC & Val $R^{2}$ & $\begin{array}{l}\text { RMSEPV } \\
\left(\mu \mathrm{g} \mathrm{cm}^{-2}\right)\end{array}$ & \% RMSEPV & References \\
\hline 9 & REIP & 0.80 & 2.71 & 9.97 & 0.81 & 2.44 & 11.15 & Guyot and Baret (1988) \\
\hline 10 & TGI & 0.78 & 2.81 & 10.35 & 0.80 & 2.51 & 11.49 & Hunt et al. (2011) \\
\hline Chl-b & & $(n=117)$ & & & $(n=50)$ & & & \\
\hline 1 & $\mathrm{NDSI}_{406,525}$ & 0.78 & 0.73 & 9.05 & 0.82 & 0.56 & 9.59 & Current study \\
\hline 2 & Carter 1 & 0.67 & 0.88 & 10.86 & 0.56 & 0.79 & 13.49 & Carter (1994) \\
\hline 3 & TGI & 0.64 & 0.90 & 11.15 & 0.63 & 0.76 & 12.90 & Hunt et al. (2011) \\
\hline 4 & GM1 & 0.64 & 0.90 & 11.10 & 0.63 & 0.77 & 13.16 & Gitelson and Merzlyak (1997) \\
\hline 5 & Clgreen & 0.63 & 0.91 & 11.25 & 0.62 & 0.78 & 13.22 & Gitelson et al. (2005) \\
\hline 6 & TCARI & 0.62 & 0.92 & 11.37 & 0.61 & 0.78 & 13.26 & Haboudane et al. (2002) \\
\hline 7 & Datt1 & 0.60 & 0.95 & 11.71 & 0.56 & 0.85 & 14.42 & Datt (1998) \\
\hline 8 & REIP & 0.59 & 0.96 & 11.84 & 0.54 & 0.84 & 14.30 & Guyot and Baret (1988) \\
\hline 9 & MCARI & 0.59 & 0.96 & 11.84 & 0.54 & 0.84 & 14.34 & Haboudane et al. (2002) \\
\hline 10 & NDRE & 0.58 & 0.97 & 11.84 & 0.55 & 0.85 & 14.45 & Barnes et al. (2000) \\
\hline TChl & & $(n=116)$ & & & $(n=50)$ & & & \\
\hline 1 & $\mathrm{NDSI}_{406,614}$ & 0.86 & 2.82 & 8.03 & 0.87 & 2.51 & 9.08 & Current study \\
\hline 2 & $\begin{array}{l}\text { GM1/Carte } \\
\text { r } 1\end{array}$ & 0.85 & 2.91 & 8.30 & 0.85 & 2.61 & 9.42 & Current study \\
\hline 3 & $\begin{array}{l}\text { GM1- } \\
\text { Carter } 1\end{array}$ & 0.83 & 3.05 & 8.70 & 0.84 & 2.68 & 9.69 & Current study \\
\hline 4 & Carter 1 & 0.80 & 3.30 & 9.42 & 0.79 & 3.07 & 11.09 & Carter (1994) \\
\hline 5 & GM1 & 0.79 & 3.38 & 9.63 & 0.81 & 2.94 & 10.63 & Gitelson and Merzlyak (1997) \\
\hline 6 & Clgreen & 0.79 & 3.39 & 9.66 & 0.81 & 2.95 & 10.65 & Gitelson et al. (2005) \\
\hline 7 & ZMI & 0.79 & 3.40 & 9.68 & 0.77 & 3.28 & 11.84 & Zarco-Tejada et al. (2001) \\
\hline 8 & Clred-edge & 0.79 & 3.42 & 9.76 & 0.77 & 3.22 & 11.65 & Gitelson et al. (2005) \\
\hline 9 & GM2 & 0.79 & 3.44 & 9.81 & 0.76 & 3.31 & 11.95 & Gitelson and Merzlyak (1997) \\
\hline 10 & TGI & 0.77 & 3.55 & 10.12 & 0.78 & 3.14 & 11.34 & Hunt et al. (2011) \\
\hline
\end{tabular}

All $\mathrm{R}^{2}$ values are significant to $P<0.0001$.

${ }^{1}$. Based on $\mathrm{R}^{2}$ of all samples (Supplementary Table S6) 

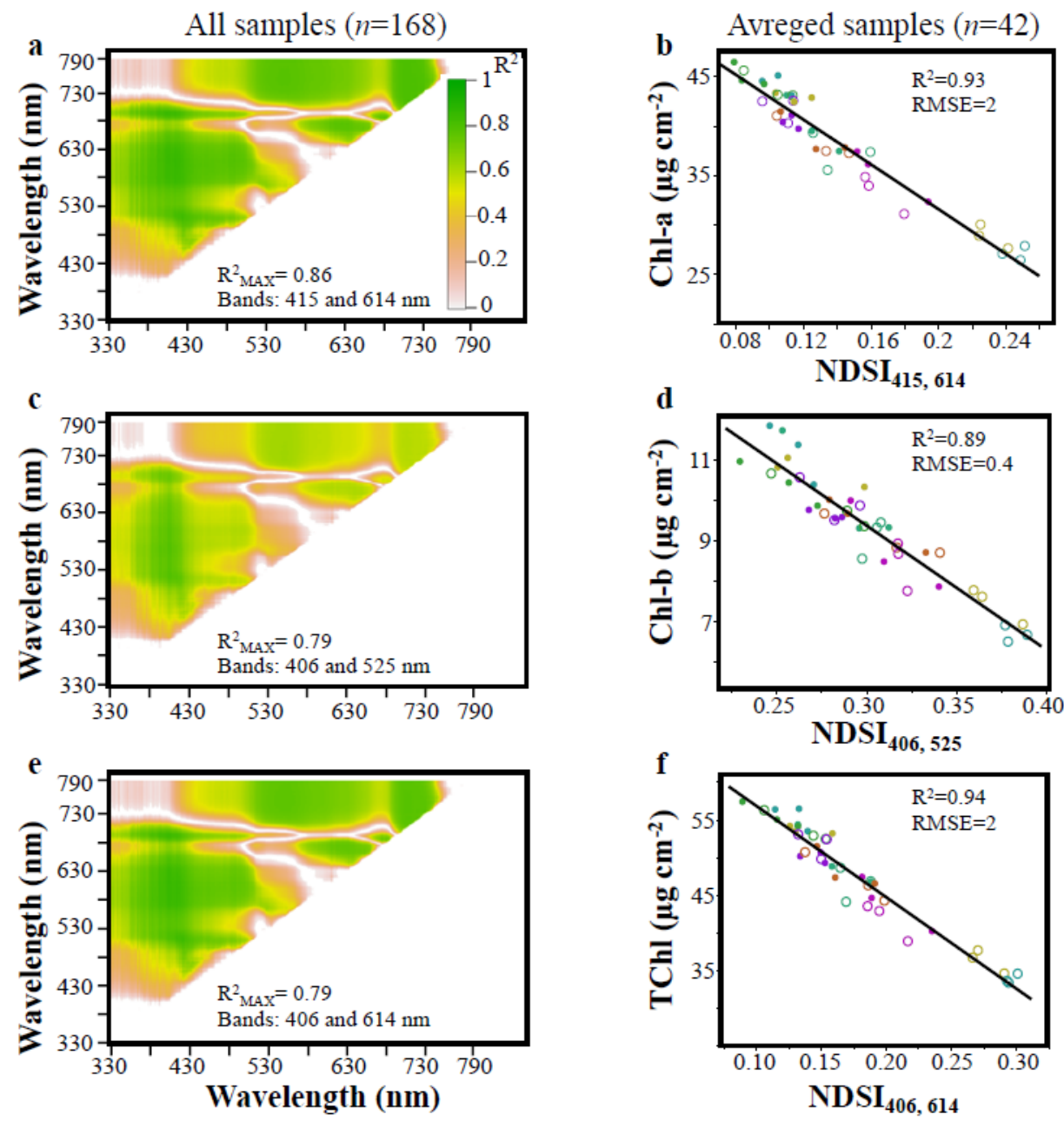

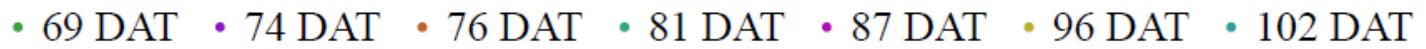

Figure 1. All possible two-band combinations by normalized difference vegetation index (NDSI) heat maps $\mathrm{R}^{2}$ values $(P<0.0001)$ for regression with $\mathrm{Chl}-\mathrm{a}, \mathrm{Chl}-\mathrm{b}$, and TChl content on all 168 samples $(\mathbf{a}, \mathbf{c}$, and e). Linear regression of $\mathrm{Chl}-\mathrm{a}, \mathrm{Chl}-\mathrm{b}$, and $\mathrm{TChl}(n=42)$ with their corresponding highest-ranking NDSI based on averaged NDSI values per genotype, irrigation regime and DAT (b, $\mathbf{d}$, and $\mathbf{f}$ ) the black lines are the trend line. Chl-a (a-b), Chl-b (c-d), and TChl (e-f). Hollow and filled dots stand for waterlimited (WL) and well-watered (WW), respectively. RMSE stands for root mean square error; DAT stands for days after transplant. 

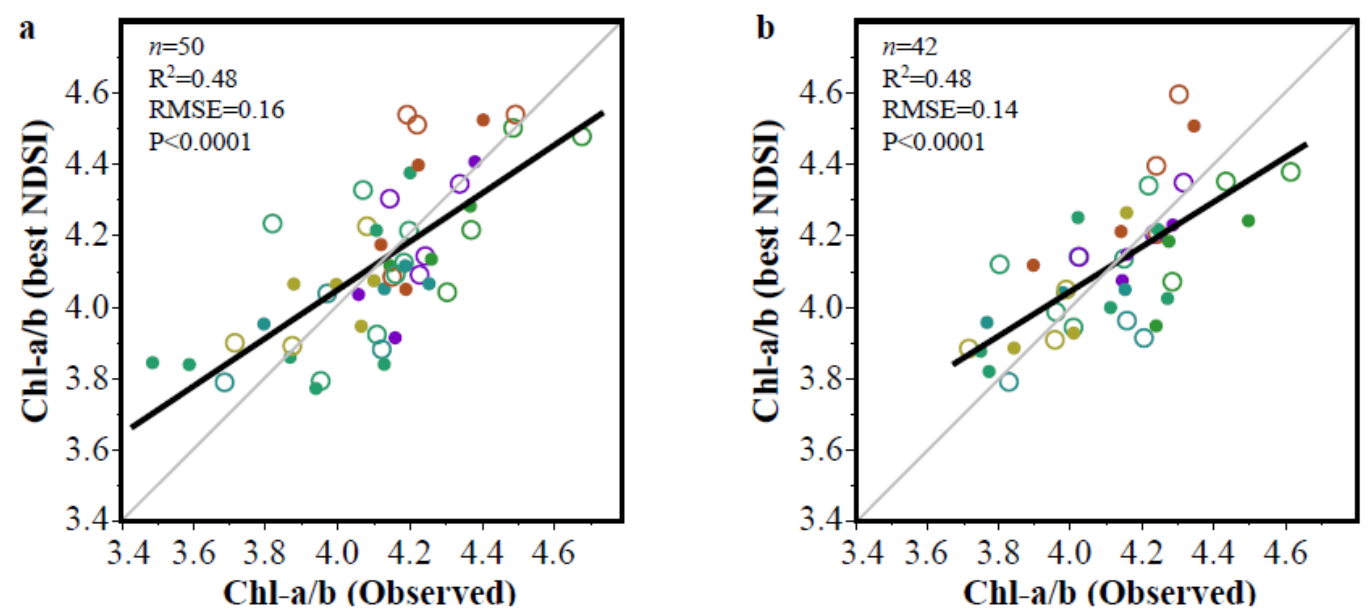

\section{- $69 \mathrm{DAT} \cdot 74 \mathrm{DAT} \cdot 76 \mathrm{DAT} \cdot 81 \mathrm{DAT} \cdot 87 \mathrm{DAT} \cdot 96 \mathrm{DAT} \cdot 102 \mathrm{DAT}$}

Figure 2. Quality of $\mathrm{Chl}-\mathrm{a} / \mathrm{b}$ spectral estimation by normalized difference spectral index (NDSI). The $\mathrm{Chl}-\mathrm{a} / \mathrm{b}$ (observed) data was acquired by extraction of Chl-a and Chl-b. The Chl-a/b (best NDSI) data was calculated by applying the top (NDSI estimating Chl-a and Chl-b (Table 1). The Val data set is presented in Table 1 (a). Averaged values per genotype, irrigation regime and DAT as presented in Fig. $1 \mathrm{~b}, \mathrm{~d}$, and $\mathrm{f}(\mathrm{b})$. DAT stands for days after transplant. Hollow and filled dots stand for waterlimited (WL) and well-watered (WW), respectively; the black lines are the trend lines and the gray lines are the 1:1 lines.

The partial least squares regression (PLSR) model did not have an advantage on the vegetation indices (VIs)

The RMSE obtained for the estimated Chl-a, Chl-b and TChl concentrations by PLSR models (Table 2) are small enough to fit 12, 14, and 11 times, respectively, in the observed range of concentrations (Fig. 3 a, c, and e). The estimation quality by PLSR and VIs (Table 1) in terms of $\mathrm{R}^{2}$ and RMSE was similar (Herrmann et al. 2011) for each of the chlorophylls. The VIs based on two to a few spectral bands and the PSLR based on 391 spectral bands resulted similarly showing no advantage to either of them. The PLSR coefficients of the models (Fig. $3 \mathrm{~b}$, d, and f) are all showing the importance of the shortest wavelengths in agreement with the 406 and 415 $\mathrm{nm}$ wavelengths selected by the NDSIs (Fig. $1 \mathrm{a}, \mathrm{c}$, and e). The combined effect of the Chl-a and Chl-b coefficients can be seen in the TChl coefficients in the enhancement in the shortest 
wavelengths as well as the contradicting trends between 500 and $550 \mathrm{~nm}$ as well as around 700 $\mathrm{nm}$. These insights support the stability of the models to be able to assess Chl-a and Chl-b and their sum as well as the ability to obtain $\mathrm{Chl}-\mathrm{a} / \mathrm{b}$ estimation (Fig. 4). The $\mathrm{Chl}-\mathrm{a} / \mathrm{b}$ estimation based on the PLSR models (Fig. 4) is showing improved $\mathrm{R}^{2}$ and RMSE in comparison to the VIs for the Val data set (Fig. 2a) as well as for the averaged samples (Fig. 2b) as was done for the VIs (Fig. 1 b, d, and f). As expected the averaged samples data resulted in the smallest RMSE value. The NDSI results (Fig. $1 \mathrm{a}, \mathrm{c}$, and e) support using the spectral range of 400 to $790 \mathrm{~nm}$ for the PLSR analysis.

Table 2. The Chl-a, Chl-b, and TChl estimation based on PLSR model.

\begin{tabular}{lcccccc}
\hline Chlorophyll & Cal R & $\begin{array}{c}\text { RMSEPC } \\
\left(\mu \mathrm{g} \mathrm{cm}^{-2}\right)\end{array}$ & \% RMSEPC & Val R & $\begin{array}{l}\text { RMSEPV } \\
\left(\mu \mathrm{g} \mathrm{cm}^{-2}\right)\end{array}$ & \% RMSEPV \\
\hline Chl-a & 0.88 & 2.11 & 7.76 & 0.86 & 2.08 & 9.52 \\
Chl-b & 0.80 & 0.66 & 8.10 & 0.81 & 0.57 & 9.63 \\
TChl & 0.87 & 2.68 & 7.63 & 0.86 & 2.51 & 9.05 \\
\hline
\end{tabular}



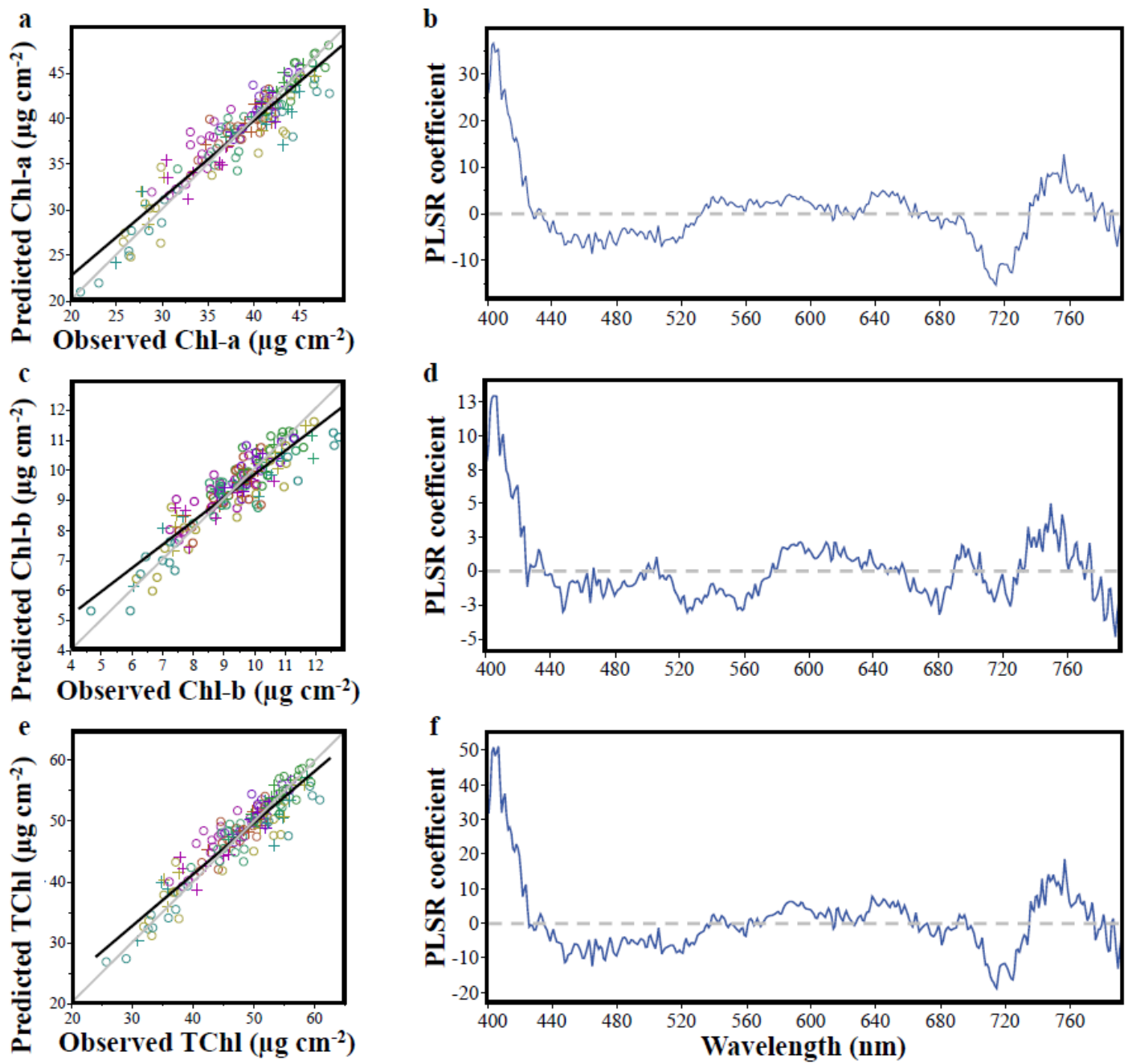

$$
\text { - } 69 \mathrm{DAT} \cdot 74 \mathrm{DAT} \cdot 76 \mathrm{DAT} \cdot 81 \mathrm{DAT} \cdot 87 \mathrm{DAT} \cdot 96 \mathrm{DAT} \cdot 102 \mathrm{DAT}
$$

Figure 3. Chl-a, Chl-b, and TChl content estimation by partial least squares (PLSR) models. Observed vs predicted chlorophyll values (a, c, and e), solid black lines are calibration (Cal) best fit lines and 1:1 lines are gray, Circle and plus markers represent Cal and Val samples, respectively. The PLSR coefficients for each of the models $(b, d$, and $\mathbf{f})$, solid blue lines are coefficient values and dashed gray lines are the zero-coefficient value. Chl-a (a-b), Chl-b (c-d), and TChl (e-f). 

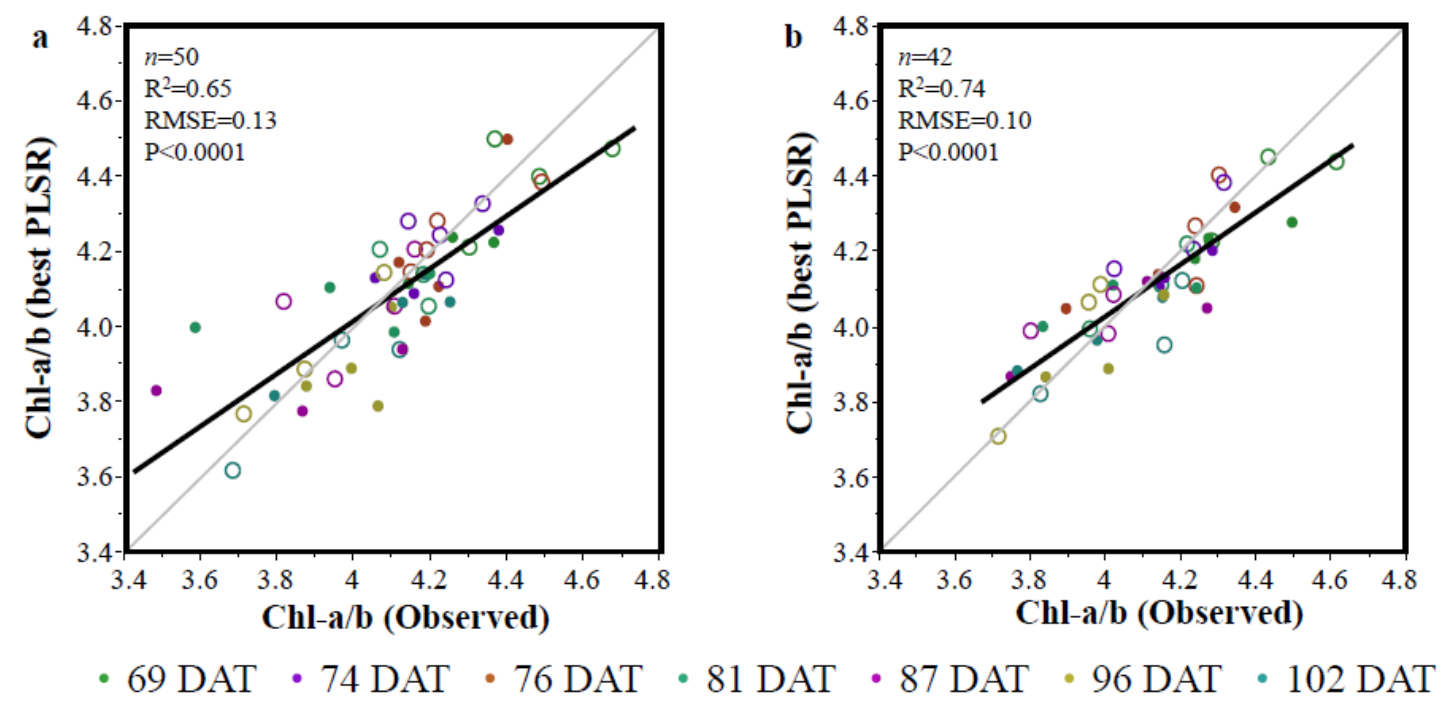

Figure 4. Quality of $\mathrm{Chl}-\mathrm{a} / \mathrm{b}$ spectral estimation. The $\mathrm{Chl}-\mathrm{a} / \mathrm{b}$ (observed) data was acquired by extraction of Chl-a and Chl-b. The Chl-a/b (best PLSR) data was calculated by applying the PLSR models estimating Chl-a and Chl-b (Table 2). The Val data set is presented in Table 2. Hollow and filled dots stand for water-limited (WL) and well-watered (WW), respectively (a). Averaged values per genotype, irrigation regime and DAT as presented in Fig. 3 b, $d$, and $f(b)$. The black lines are the trend lines and the gray lines are the 1:1 lines. Hollow and filled dots stand for water-limited (WL) and well-watered (WW), respectively.

\section{Concluding remarks}

The current study aimed to spectrally assess Chl-a and Chl-b to identify the best VI or VIs for indirectly estimate $\mathrm{Chl}-\mathrm{a} / \mathrm{b}$. While there were no significant differences in $\mathrm{Chl}-\mathrm{a} / \mathrm{b}$ values between WW and WL treatments, the active range of the measured or predicted $\mathrm{Chl}-\mathrm{a} / \mathrm{b}$ values were five to six times the RMSE values for the non-averaged samples. Thus, it was concluded that: $i$ ) the new VIs that were developed in the current study resulted in high accuracy of Chl-a and Chl-b estimation; ii) the developed VIs were able to indirectly estimate $\mathrm{Chl}-\mathrm{a} / \mathrm{b}$; and iii) the VIs developed in the current study performed similarly to the PLSR. The model quality achieved by VIs developed in the current study in comparison to PLSR supports sensors with few spectral bands for practical use while hyperspectral sensors are used for research to identify these spectral bands. The developed models should be tested in additional crops for breeding 
projects. Under more severe water stress scenarios, resulting in a wider range of $\mathrm{Chl}-\mathrm{a} / \mathrm{b}$ values, the models are expected to perform even better than in the current study. This concept of Chl$\mathrm{a}$ and $\mathrm{Chl}-\mathrm{b}$ direct estimation to indirectly assess $\mathrm{Chl}-\mathrm{a} / \mathrm{b}$ should be tested also for canopy level spectral data collection. The current study presented a new tool, based on a spectral assessment of Chl-a and Chl-b for non-destructive estimation of $\mathrm{Chl}-\mathrm{a} / \mathrm{b}$ which can serve as a basis for future wheat breeding efforts. The ability to assess Chl-a/b in-vivo, non-destructively by spectral sensing will improve breeding projects efficiency.

Acknowledgments This study was partially supported by the U.S. Agency for International Development Middle East Research and Cooperation (grant \# M34-037), and the Dutch Ministry of Foreign Affairs under Dutch development / foreign policy (Project WheatMAX), the Hebrew University of Jerusalem Intramural Research Fund Career Development, and the International School of Agricultural Sciences.

Author contributions statement G.M., H.B., Z.P. and I.H. designed the study. G.M., H.B. and U.K. performed the experiments and analyzed the data. G.M., H.B., Z.P. and I.H. wrote the manuscript. All authors discussed the results and their implications and revised the manuscript.

\section{References}

Abbo S, Pinhasi van-Oss R, Gopher A, Saranga Y, Ofner I, Peleg Z (2014) Plant domestication versus crop evolution: a conceptual framework for cereals and grain legumes. Trends in Plant Science 19:351-360. 
Ashraf M, Harris PJC (2013) Photosynthesis under stressful environments: An overview. Photosynthetica 51:163-190.

Bacher H, Zhu F, Gao T, Liu K, Dhatt BK, Awada T, Zhang C, Distelfeld A, Yu H, Peleg Z, Walia H (2021) Wild emmer introgression alters root-to-shoot growth dynamics in durum wheat in response to water stress. Plant Physiology. in press (doi:10.1093/plphys/kiab292)

Banerjee BP, Joshi S, Thoday-Kennedy E, Pasam RK, Tibbits J, Hayden M, Spangenberg G, Kant S (2020) High-throughput phenotyping using digital and hyperspectral imaging-derived biomarkers for genotypic nitrogen response. Journal of Experimental Botany 71:4604-4615.

Bannari A, Khurshid KS, Staenz K, Schwarz JW (2007) A comparison of hyperspectral chlorophyll indices for wheat crop chlorophyll content estimation using laboratory reflectance measurements. IEEE Transactions on Geoscience and Remote Sensing 45:3063-3074.

Bannari A, Morin D, Bonn F, Huete AR (1995) A review of vegetation indices. Remote Sensing Reviews 13:95-120

Barnes E, M., Clarke T, R., Richards S, E., Colaizzi P, D., Haberland J, Kostrewski M, Waller P, Choi C, Riley E, Tompson T, Lascano R, J., Li H, Moran M, S. (2000) Coincident detection of crop water stress, nitrogen status and canopy density using ground-based multispectral data. In: the $5 \mathrm{fh}$ International Conference on Precision Agriculture, Bloomington, MN, USA.

Carter GA (1994) Ratios of leaf reflectances in narrow wavebands as indicators of plant stress. International Journal of Remote Sensing 15:697-703

Chappelle EW, Kim MS, McMurtrey JE (1992) Ratio analysis of reflectance spectra (RARS): an algorithm for the remote estimation of the concentrations of chlorophyll $a$, chlorophyll $b$, and carotenoids in soybean leaves. Remote Sensing of Environment 39:239-247.

Chen X, Dong Z, Liu J, Wang H, Zhang Y, Chen T, Du Y, Shao L, Xie J (2020) Hyperspectral characteristics and quantitative analysis of leaf chlorophyll by reflectance spectroscopy based on a genetic algorithm in combination with partial least squares regression. Spectrochimica Acta Part a-Molecular and Biomolecular Spectroscopy 243:118786.

Croce R, van Amerongen H (2014) Natural strategies for photosynthetic light harvesting. Nature Chemical Biology 10:492-501. 
Croft H, Chen JM (2018) 3.09 - Leaf pigment content. Comprehensive Remote Sensing 3:117142.

Croft H, Chen JM, Luo X, Bartlett P, Chen B, Staebler RM (2017) Leaf chlorophyll content as a proxy for leaf photosynthetic capacity. Global Change Biology 23:3513-3524.

Datt B (1998) Remote Sensing of Chlorophyll a, Chlorophyll b, Chlorophyll $a+b$, and Total Carotenoid Content in Eucalyptus Leaves. Remote Sensing of Environment 66:111-121. Gausman HW, Allen WA (1973) Optical parameters of leaves of 30 plant species. Plant Physiology 52:57-62.

Giovos R, Tassopoulos D, Kalivas D, Lougkos N, Priovolou A (2021) Remote sensing vegetation indices in viticulture: A critical review. Agriculture 11:457.

Gitelson AA (2011) Non-destructive estimation of foliar pigment (chlorophylls, carotenoids, and anthocyanins) contents: evaluating a semi-analytical three-band model. In: Thenkabail PS, Lyon JG, Huete A (eds) Hyperspectral remote sensing of vegetation. CRC Press, Boca Raton, pp 141-166

Gitelson AA, Gritz Y, Merzlyak MN (2003) Relationships between leaf chlorophyll content and spectral reflectance and algorithms for non-destructive chlorophyll assessment in higher plant leaves. Journal of Plant Physiology 160:271-282

Gitelson AA, Keydan GP, Merzlyak MN (2006) Three-band model for noninvasive estimation of chlorophyll, carotenoids, and anthocyanin contents in higher plant leaves. Geospatial Research Letters 33: L11402.

Gitelson AA, Merzlyak MN (1997) Remote estimation of chlorophyll content in higher plant leaves. International Journal of Remote Sensing 18:2691-2697.

Gitelson AA, Vina A, Ciganda V, Rundquist DC, Arkebauer TJ (2005) Remote estimation of canopy chlorophyll content in crops. Geospatial Research Letters 32: L08403.

Golan G, Hendel E, Espitia GEM, Schwartz N, Peleg Z (2018) Activation of seminal root primordia during wheat domestication reveals underlying mechanisms of plant resilience. Plant, Cell and Environment 41:755-766.

Guo YY, Yu HY, Kong DS, Yan F, Zhang YJ (2016) Effects of drought stress on growth and chlorophyll fluorescence of Lycium ruthenicum Murr. seedlings. Photosynthetica 54:524-531. 
Guru T, Padma V, Reddy DVV, Rao PR, Sanjeeva Rao D, Ramesh T, Radhakrishna KV (2017) Natural variation of top three leaf traits and their association with grain yield in rice hybrids. Indian Journal of Plant Physiology 22:141-146.

Guyot G, Baret F Utilisation de la haute resolution spectrale pour suivre l'etat des couverts vegetaux. In: Esa (ed) 4th International Colloquium "Spectral signatures of objects in remote sensing", Aussois, 18 - 22 January 1988. Paris: ESA pablication, pp 279-286

Haboudane D, Miller JR, Tremblay N, Zarco-Tejada PJ, Dextraze L (2002) Integrated narrow-band vegetation indices for prediction of crop chlorophyll content for application to precision agriculture. Remote Sensing of Environment 81:416-426

Hallik L, Kazantsev T, Kuusk A, Galmes J, Tomas M, Niinemets U (2017) Generality of relationships between leaf pigment contents and spectral vegetation indices in Mallorca (Spain). Regional Environmental Change 17:2097-2109.

Herrmann I, Karnieli A, Bonfil D, J., Cohen Y, Alchanatis V (2010) SWIR-based spectral indices for assessing nitrogen content in potato fields. International Journal of Remote Sensing 31:51275143.

Herrmann I, Pimstein A, Karnieli A, Cohen Y, Alchanatis V, Bonfil D, J. (2011) LAl assessment of wheat and potato crops by VEN $\mu$ S and Sentinel- 2 bands. Remote Sensing of Environment $115: 2141-2151$.

Hunt ER, Jr., Daughtry CST, Eitel JUH, Long DS (2011) Remote sensing leaf chlorophyll content using a visible band index. Agronomy Journal 103:1090-1099.

Inoue Y, Penuelas J, Miyata A, Mano M (2008) Normalized difference spectral indices for estimating photosynthetic efficiency and capacity at a canopy scale derived from hyperspectral and CO2 flux measurements in rice. Remote Sensing of Environment 112:156172.

Joynson R, Molero G, Coombes B, Gardiner L-J, Rivera-Amado C, Piñera-Chávez FJ, Evans JR, Furbank RT, Reynolds MP, Hall A (2021) Uncovering candidate genes involved in photosynthetic capacity using unexplored genetic variation in spring wheat. Plant Biotechnology Journal, in press (https://doi.org/10.1111/pbi.13568). 
Lenaerts B, Collard BCY, Demont M (2019) Review: Improving global food security through accelerated plant breeding. Plant Science 287: 110207.

Lopes DdC, Moura LdO, Steidle Neto AJ, Louback Ferraz LdC, Carlos LdA, Martins LM (2017) Spectral indices for non-destructive determination of lettuce pigments. Food Analytical Methods 10:2807-2814.

Main R, Cho MA, Mathieu R, O'Kennedy MM, Ramoelo A, Koch S (2011) An investigation into robust spectral indices for leaf chlorophyll estimation. Isprs Journal of Photogrammetry and Remote Sensing 66:751-761.

McKinney W (2010) Data Structures for Statistical Computing in Python, Proceedings of the 9th Python in Science Conference, 51-56.

Moran R (1982) Formulae for Determination of Chlorophyllous Pigments Extracted with N,N-

Dimethylformamide. Plant Physiology 69:1376-1381.

Moran R, Porath D (1980) Chlorophyll determination in intact tissues using N,N-

Dimethylformamide. Plant Physiology 65:478-479.

Myers SS, Smith MR, Guth S, Golden CD, Vaitla B, Mueller ND, Dangour AD, Huybers P (2017)

Climate Change and Global Food Systems: Potential Impacts on Food Security and Undernutrition. Annual Review of Public Health, 38:259-277.

Pedregosa f, Varoquaux G, Gramfort A, Michel V, Thirion B, Grisel O, Blondel M, Prettenhofer P, Weiss R, Dubourg V, Vanderplas J, Passos A, Cournapeau D, Brucher M, Perrot M, Duchesnay E (2011) Scikit-learn: Machine Learning in Python, Journal of Machine Learning Research, 12, 2825-2830.

Peleg Z, Fahima T, Abbo S, Krugman T, Nevo E, Yakir D, Saranga Y (2005) Genetic diversity for drought resistance in wild emmer wheat and its ecogeographical associations. Plant, Cell \& Environment 28:176-191.

Pyke KA, Jellings AJ, Leech RM (1990) Variation in mesophyll cell number and size in wheat leaves. Annals of Botany 65:679-683.

Ray DK, Mueller ND, West PC, Foley JA (2013) Yield Trends Are Insufficient to Double Global Crop Production by 2050. PLoS ONE 8: e66428. 
Sade N, Peleg Z (2020) Future challenges for global food security under climate change. Plant Science 295:110467.

Singh A, Serbin SP, McNeil BE, Kingdon CC, Townsend PA (2015) Imaging spectroscopy algorithms for mapping canopy foliar chemical and morphological traits and their uncertainties. Ecological Applications 25:2180-2197.

Sonobe R, Yamashita H, Mihara H, Morita A, Ikka T (2020) Estimation of leaf chlorophyll a, b and carotenoid contents and their ratios using hyperspectral reflectance. Remote Sensing 12: 3265.

Thenkabail PS, Mariotto I, Gumma MK, Middleton EM, Landis DR, Huemmrich KF (2013) Selection of hyperspectral narrowbands (HNBs) and composition of hyperspectral twoband vegetation indices (HVIs) for biophysical characterization and discrimination of crop types using field reflectance and hyperion/EO-1 data. IEEE Journal of Selected Topics in Applied Earth Observations and Remote Sensing 6:427-439.

Ustin SL, Jacquemoud S (2020) How the optical properties of leaves modify the absorption and scattering of energy and enhance leaf functionality. In: Cavender-Bares J, Gamon JA, Townsend PA (eds) Remote Sensing of Plant Biodiversity. Springer International Publishing, Cham, pp 349-384.

Virtanen P, Gommers R, Oliphant TE, Haberland M, Reddy T, Cournapeau D, Burovski E, Peterson P, Weckesser W, Bright J, van der Walt SJ, Brett M, Wilson J, K. Millman J, Mayorov N, Nelson ARJ, Jones E, Kern R, Larson E, Carey CJ, Polat I, Feng Y, Moore EW, VanderPlas J, Laxalde D, Perktold J, Cimrman R, Henriksen I, Quintero EA, Harris CR, Archibald AM, Ribeiro AH, Pedregosa F, van Mulbregt P (2020) SciPy 1.0: Fundamental Algorithms for Scientific Computing in Python. Nature Methods, 17(3), 261-272.

Wellburn AR (1994) The spectral determination of chlorophyll-a and chlorophyll-b as well as total carotenoids using various solvents with spectrophotometers of different resolution. Journal of Plant Physiology 144:307-313.

Wold S, Sjostrom M, Eriksson L (2001) PLS-regression: A basic tool of chemometrics. Chemometrics and Intelligent Laboratory Systems 58:109-130. 
Yamamoto A, Nakamura T, Adu-Gyamfi JJ, Saigusa M (2002) Relationship between chlorophyll content in leaves of sorghum and pigeonpea determined by extraction method and by chlorophyll meter (SPAD-502). Journal of Plant Nutrition 25:2295-2301.

Yang GJ, Liu JG, Zhao CJ, Li ZH, Huang YB, Yu HY, Xu B, Yang XD, Zhu DM, Zhang XY, Zhang RY, Feng HK, Zhao XQ, Li HL, Yang H (2017) Unmanned Aerial Vehicle Remote Sensing for FieldBased Crop Phenotyping: Current Status and Perspectives. Frontiers in Plant Science 8:1111.

Yu K, Gnyp ML, Gao CL, Miao Y, Chen X, Bareth G (2015) Estimate leaf chlorophyll of rice using reflectance indices and partial least squares. Photogrammetrie Fernerkundung Geoinformation 1:45-54.

Zarco-Tejada PJ, Miller JR, Noland TL, Mohammed GH, Sampson PH (2001) Scaling-up and model inversion methods with narrowband opticalindices for chlorophyll content estimation in closed forest canopies with hyperspectral data. IEEE Transactions on Geoscience and Remote Sensing 39:1491-1507 